\title{
Supporting Executive Function Skills in Early Childhood: Using a Peer Buddy Approach for Community, Confidence, and Citizenship
}

\author{
Kathleen I. Harris (Corresponding author) \\ Division of Education, Early Childhood Education, Seton Hill University \\ One Seton Hill Drive, Greensburg, Pennsylvania 15601, United States \\ Email: kharris@setonhill.edu
}

Received: December 1, 2015 Accepted: December 15, 2015 Published: January 8, 2016

doi:10.5296/jet.v3i1.8837ＵRL: http://dx.doi.org/10.5296/jet.v3i1.8837

\begin{abstract}
This article provides a descriptive overview of a peer buddy program designed to develop and support young children's executive functioning in early childhood classrooms. The author defines and categorizes executive function skills and analyzes their development in early childhood and benefits in the continued academic success of young children. The steps in creating a peer buddy program are explained, and a framework is provided for teachers to help the entire class develop effective executive function skills while facilitating positive social skills for classroom community building and citizenship. By supporting young children in their efforts to develop stronger executive function skills, teachers build resilience and help them discover their strengths for facilitating social interactions, problem-solving skills, and confidence in cognitive decision making to be successful citizens at home and in school.
\end{abstract}

Keywords: Executive functioning; Peers; Social skills; Citizenship; Early childhood

\section{Introduction}

On a Monday morning in early October, Miss Sara prepares the classroom for her 14 preschool children, most of whom are four years old. Upon arrival, Sawyer walks past Miss Sara into the classroom and drops her sweater and backpack on the floor. Miss Sara gently redirects Sawyer back to her cubby, but Sawyer looks over Miss Sara's shoulders and rushes over to the book corner instead to find her favorite book. After searching through the shelf, Sawyer sees that Nicole has her favorite book. Running over and grabbing it from Nicole's hands, Sawyer says in a loud voice, "That's my book! Give it to me now!" Upset, Nicole rushes over to Miss Sara in tears, telling her Sawyer has taken a book she was looking at. Miss Sara sighs as she observes Sawyer look at the cover of the book and then drops it on the shelf to go over to the sensory table, where she demands that Christopher give her the shovel 
he is using, so she can use it to put rice into a pail. When Christopher ignores Sawyer's demand, she stamps her foot and takes a handful of rice, spilling it on the floor. Finally, as circle time begins and Miss Sara leads the singing of the morning song with the children, Sawyer remains standing and staring out the window, watching birds flying to the birdfeeder, ignoring her peers and Miss Sara's directions to join the circle time activities. Miss Sara observes the entire class, wondering why Sawyer always needs additional prompting to get started in the morning and why she has so much trouble generating alternative methods of solving a problem with peers. Miss Sara asks herself, "How can I possibly do more for Sawyer than I'm already doing?"

\section{What are Executive Function Skills?}

During the course of a day at school, some children may experience challenges with executive function skills, leaving them unable to focus, curb inappropriate behaviors, and get along with peers. In some cases, young children may need stronger support strategies and deeper understanding from teachers to help them manage demands, comprehend what they know, and become effective independent learners in a classroom community (Cooper-Kahn \& Foster, 2013).

Efficient executive functioning is considered important in managing the practical demands of daily life. Related to the mental process of supervising one's own thinking and behavior to achieve a goal (Cooper-Kahn \& Foster, 2013), executive functioning is neuropsychological and involves the cognitive processes required to plan and direct activities, including task initiation and follow-through, working memory, sustained attention, performance monitoring, inhibition of impulses, and goal-directed persistence (Dawson \& Guare, 2012). Executive functioning is an umbrella term that includes the set of processes that govern goal-directed acts and flexible, adaptive responses to changes in the environment (Hughes \& Ensor, 2008). Executive functioning represents a significant advancement in understanding young children's development and unique developmental profiles of strengths and weaknesses (Cooper-Kahn \& Dietzel, 2008). Good executive functioning relies on a collection of specific operations called executive function skills, that is, self-directed actions used to purposefully modify one's own behavior in order to make a goal more or less likely to happen (Barkley, 1997). Executive function skills allow a young child to master a plan, initiating the steps and sequence in a timely manner; react effectively and appropriately to changes and challenges; and keep the goals in mind over time (Cooper-Kahn \& Foster, 2013). They also support children during daily life routines and activities (Dawson \& Guare, 2012).

Executive function skills have been variously defined by researchers (Suchy, 2009). In many cases, core executive skills work together to bring about efficient and smooth functioning (Cooper-Kahn \& Foster, 2013). Good executive functioning depends on several factors, including sound development of several different regions of the brain and opportunities for learning and practice (Cooper-Kahn \& Foster, 2013). Table 1 provides a list of the processes typically included under the umbrella of executive functioning skills and the definitions of each. 
Table 1. Executive Function Processes for Young Children

\section{Response inhibition}

- The ability to think and consider one's own actions before taking action

Working memory

- The ability to hold information in mind to complete activities

Emotional control

- The ability to control emotions to complete tasks and achieve goals

Sustained attention

- The ability to maintain attention to a situation or task despite distractions or boredom

Task initiation

- The ability to start activities and projects without procrastinating and independently consider ideas, responses, or problem-solving strategies

Planning

- The ability to decide which activities are necessary to complete a goal; the ability to make decisions about what is and is not important

Organization

- The ability to develop and maintain systems to keep track of materials and information

Time management

- The ability to realize that time is important; the ability to estimate how much time is required to complete an activity, how to allocate it, and how to stay within the limits and deadlines

Goal-directed persistence

- The ability to set a goal and follow through to its completion

Flexibility

- The ability to revise plans if changes occur in a routine schedule; the ability to accommodate and adapt to situations

Metacognition

- The ability to step back from a situation and view oneself from a distance; the ability to observe how to problem solve in a situation

Note: Executive function processes for young children. Adapted from Dawson, D., \& Guare, P. (2010). Executive skills in children and adolescents: A practical guide to assessment and intervention. New York, NY: Guildford Press. 
Executive function delays in some young children vary in the pattern and intensity of strengths and weaknesses in their executive developmental profile (Cooper-Kahn \& Foster, 2013). At times, the pace at which children develop executive control may vary widely (Cooper-Kahn \& Dietzel, 2008); for example, some children may catch up during middle childhood, but others continue to experience executive weaknesses as teens and young adults. For most young children, though, no known cause of such delays has been determined (Cooper-Kahn \& Dietzel, 2008). Many times these may appear as developmental weaknesses because no single definitive event or variable interfered with brain development. In many cases, weaknesses in executive functioning may result from inefficient communication among brain regions instead of any overt behavior. Research has shown, however, that exposure to alcohol or certain drugs during a mother's pregnancy as well as premature birth could bring higher risk for delays in cognitive development (Cooper-Kahn \& Dietzel, 2008). In addition, physical health and emotional stress can affect executive functioning. Problems in any one of these developmental domains may lead to significant weaknesses in executive functioning.

\section{Development of Executive Function Skills in Childhood}

The development of executive function skills is related both to the biological process of brain maturation (nature) and experience (nurture). As children develop executive function skills, one must remember that these skills develop in the context of the whole person. Some people are born with the gift of strong executive skills; others are challenged in this arena (Cooper-Kahn \& Foster, 2013). At the same time executive skills develop, a young child also develops emotionally, socially, and physically; thus, experiences in the environment affect the child's self-image (Cooper-Kahn \& Dietzel, 2008). The responses and care young children receive from caregivers, families, and peers may contribute in a positive or negative manner to a child's self-concept and development of self.

Effective functions develop as early as infancy when babies develop the ability to manage their own behavior to meet specific goals (Carpenter, Nagell, \& Tomasello, 1998). For example, infants often focus on caregivers' faces or follow the sound of their voices. Executive function skills develop gradually and in a clear progression through the first two decades of life (Dawson \& Guare, 2012). At four months of age, infants have the capacity for some executive functioning as shown by their attention and memory (Carpenter et al., 1998). Researchers on infants have reported that response inhibition, working memory, emotional control, and attention all develop early, that is, in the first six to 12 months (Cooper-Kahn \& Dietzel, 2008). By age three, young children demonstrate working memory, the ability to shift intentional focus, and inhibitory control (Hughes, 1998), which has the potential to improve between ages three and six (Montgomery \& Koeltzow, 2010) and supports children's adjustment to academic and behavioral expectations at preschool (Cartwright, 2012). For example, at three years of age, they can consider two rules and act on them. At four and five years of age, they can comprehend that appearance does not always equal reality. Cognitive flexibility also increases during early childhood and between two and five years of age, when young children may succeed at shifting actions according to changing rules. Although executive functioning continues to mature across developmental stages from infancy to adulthood, many critical developments occur during the early childhood years (Cartwright, 
2012). From the moment young children initially interact with their environments, parents and teachers have expectations for the way they will use executive function skills to work out many of the demands placed on them, including practicing the self-regulation behaviors required to act as responsible citizens in the classroom and the planning and initiating the skills required to complete simple chores and homework at home.

\section{Types of Executive Function Skills}

Executive functioning includes six abilities: (a) managing time and attention, (b) switching focus, (c) planning and organizing, (d) remembering details, (e) curbing inappropriate speech or behaviors, and (f) integrating past experiences with present action. As a young child grows, parents and teachers can see how executive function skills improve. For example, the ability to be more independent with simple routines, such as dressing, brushing teeth, putting toys away after playing, and performing basic life tasks at home. As a child learns, two different types of executive skills develop. The first comprises thinking skills that allow the child to select and achieve goals or develop solutions to problems (Cooper-Kahn \& Dietzel, 2008), including working memory, planning, organization, time management, and metacognition. The second type of executive function skills comprises doing skills, those that guide and support children's actions when completing an activity, such as goal-directed persistence, flexibility, sustained attention, emotional control, response inhibition, and task initiation. Table 2 describes the two different types of executive skills for young children.

Teachers must consider the child's needs and strengths and understand his or her experiences when selecting a supportive, helpful intervention. For example, critical executive function skills young children should practice for a successful transition to kindergarten include following rules and directions given by a teacher, taking turns with peers and playing appropriately with peers and classroom materials (Missall \& Hojnoski, 2008). Understanding the way each executive skill functions, that is, thinking or doing, is necessary to establish whether the goal of an intervention strategy is to help a child think or behave differently (Cooper-Kahn \& Dietzel, 2008). One intervention strategy that has potential to support the development of executive function skills for all young children is a peer buddy program. Buddy is an American term that means "a very special, close friend" (Collins, 2005). A substantial body of evidence suggests that peers working together may significantly impact academic achievement and instruction, behavior management, and positive social interactions (Brown, Odom, McConnell, \& Rathel, 2008; Dawson \& Guare, 2012). Young children working, playing, and learning together have the potential to develop and promote appropriate executive function skills through experience and practice in the classroom community, thus becoming more independent and self-directed learners (Dawson \& Guare, 2012). In addition, using peers as intervention agents for promoting executive function skills and social interaction is a naturalistic teaching strategy that allows young children opportunities to learn in the context of ongoing classroom activities and routines (Grisham-Brown, Hemmeter, \& Pretti-Frontczak, 2005); furthermore, naturalistic teaching procedures have been empirically validated as effective for children with a variety of learning needs (McCormick, 1997). Peers may model how to join in an activity with others, teach a classmate how to interpret a picture schedule or follow directions, support a child when taking turns, encourage a child to stay on task during class activities, teach classroom routines, 
and tutor in a specific skill (Copeland et al., 2002). The effectiveness of this intervention has been demonstrated at all grade levels, across all developmental levels and individual children's needs and supports young children who experience social difficulties associated with weakness in executive functioning (Gewirtz, Stanton-Chapman, \& Reeve, 2009; Plumer, 2007).

Table 2. Types and Examples of Executive Function Skills for Young Children

Response inhibition

\section{Executive Function Skills Relating to Doing}

- A young child can wait in line with peers until his or her turn without being disruptive.

Emotional control

- A young child can remain composed if not getting his or her own way during a board game.

Sustained attention

- A young child can sit in circle time while the teacher reads a picture book to the class.

Task initiation

- A young child can play blocks with a peer immediately after directions are given by a teacher.

Goal-directed persistence

- A young child has a specific role and plan during dramatic play with peers.

Flexibility

- A young child can easily adjust when a transition occurs or change in a routine schedule.

Planning

\section{Executive Function Skills Relating to Thinking (Cognitive Domain)}

- A young child can consider a solution to a conflict with a peer when both want to play with the same toy.

Organization

- A young child takes time to place toys and art materials in designated learning centers during clean-up time.

Working memory

- A young child can remember and successfully follow a one- or -two-step directions in a game with peers during outside play.

Time management

- A young child can complete an art activity within the time limit set by a teacher.

Metacognition

- A young child can change a behavior in response to feedback from a teacher or family member. 


\section{Advantages of a Peer Buddy Program to Support Executive Functioning}

Successful peer-based intervention strategies have been researched for decades (Mathur \& Ruterford, 1991). For example, English, Goldstein, Shafer, and Kaczmarek (1997) implemented a peer buddy strategy called "stay, play, and talk" for children with and without disabilities. The buddy program was effective in improving several social communication skills (e.g., verbal requests and commands) of young children with disabilities. In another study, Laushey and Helflin (2000) used peer buddy intervention to improve social skills for kindergartners with autism spectrum disorder (ASD) and their peers. Researchers trained children with ASD and peers in social skills. Results indicated children with ASD demonstrated increased interaction with peers and also improved additional social skills, such as taking turns, obtaining peer attention, and making eye contact. Peer buddy programs were also implemented in similar elementary classrooms to increase peer interactions for children with autism and children with attention deficit hyperactivity disorder (ADHD) (Brown et al., 2008; Plumer \& Stoner, 2005). In a similar study, Carter, Cushing, Clark, and Kennedy (2005) demonstrated the social benefits of a peer buddy training program with secondary students with intellectual disabilities. Finally, Tao and Odom (2006) examined a peer buddy system with four typically developing young children for increasing social interaction with siblings who have autism. Results indicated that three of the four typical children increased social interaction with their siblings. As discussed, peer buddy programs are flexible tools for achieving important educational goals, including social acceptance, community building, and citizenship (Hughes \& Carter, 2006).

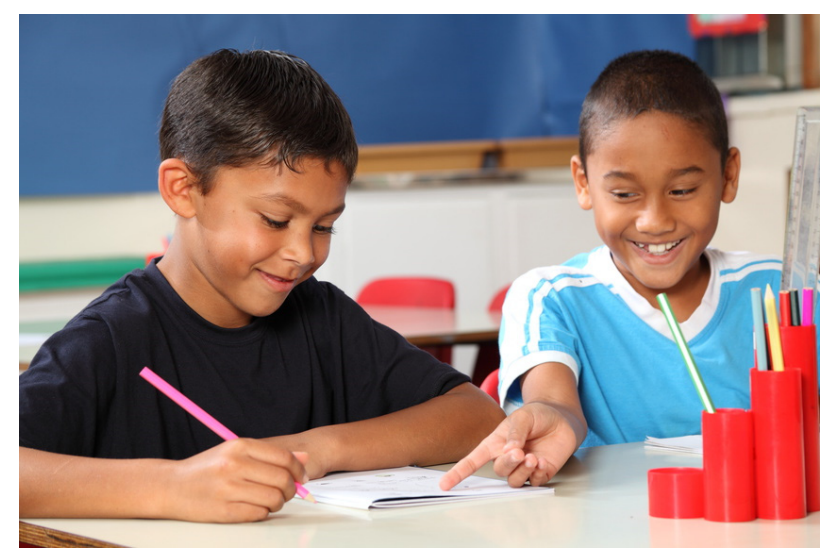

Figure 1. Peer buddy class wide programs can promote citizenship skills by gaining opportunities for social interactions with peers

Strategies like peer buddy programs in schools are highly energizing and desirable because when used effectively by teachers, this type of social intervention package is considerate of time demands on teachers and also sensitive to the lack of resources in contemporary classrooms (Dawson \& Guare, 2012). The classroom ecology, or classroom climate, has the potential to improve by supporting practices that promote a caring school community. 
Teachers can address a range of learning needs regarding executive function skills and simultaneously engage all children. A peer buddy program may also increase diversity in the classroom and provide executive function skill opportunities for all students in the classroom community. As a result, the entire class has the potential to benefit from a peer buddy program. For example, typically developing children can gain additional knowledge about executive function skills and may also learn enhanced interpersonal skills; children requiring extra support with executive function skills have the opportunity to develop new friendships while learning the capacity for self-regulation, sustained attention, emotional control, and persistence. While the peer buddy program is used, teachers can monitor progress and model appropriate behaviors to develop executive function skills. Peer buddy programs offer a practical approach for supporting executive function skills and building increased social skills for all young children (see Figure 1). Peer buddies have the potential to reduce stress and fear of new tasks; they can serve as role models for on-task behaviors and can help a child stay focused during playtime and class activities (Jackson \& Campbell, 2009).

In helping young children develop executive function skills (e.g., listening, following directions, paying attention, focusing, completing daily routines and activities, putting toys and materials away, exercising inhibitory control, applying nonverbal and verbal memory), teachers should include daily opportunities to practice executive function skills and social skills (e.g., taking turns, making eye contact, conversing). The following section offers a set of eight steps teachers can follow when designing and implementing a peer buddy program to support executive functioning in early childhood settings.

\section{Step One for Implementing a Peer Buddy Program: Assessing Current Executive Functioning}

Before instituting a peer buddy program to support executive function skills, teachers should consider children's current competence. Throughout daily activities and routines, children in the class may practice a variety of executive function skills. For example, a few children may be competent with taking turns and sharing toys with peers, and others can sit through circle time for 15 minutes. Assessing executive function skills in the classroom may take place in a variety of ways: Teachers can use anecdotal notes by describing the setting, activity, participants, and the behaviors observed during the interaction and/or direct observations by describing the child's executive skill strengths and weaknesses. They may also have opportunities to analyze data on a child's executive functioning from past evaluations. Other tools include social skill assessments like the Social Skills Improvement System (SSIS) Rating Scales (Gresham \& Elliott, 2008) or questionnaires and interviews with family members (Sansosti, 2010); survey questions could include descriptions of executive function skills, which family members rate in terms of the child's performance (Dawson \& Guare, 2009).

\section{Step 2: Identifying Children Who Would Benefit From Participating}

After collecting data from interviews and questionnaires submitted by family members and analyzing observation notes, teachers may recognize children in the class who need additional support to develop executive function skills. During this process, teachers should remember that development varies (Cooper-Kahn \& Dietzel, 2008). They should also 
consider incorporating goals into the child's Individual Education Program (IEP) to further the development of executive function skills at school and at home. Teachers should also consider the standards addressing the curriculum, instructional strategies, and assessments. Children who may benefit from a peer buddy program could be those who have problems taking turns or those who may have difficulty choosing a toy and indecisively move from one toy to another or those who cannot focus while the teacher reads during story time.

\section{Step 3: Determining Specific Goals}

Once children have been identified to participate in the peer buddy program, the teacher should determine the appropriate executive function skills and goals for each child. For example, a goal for a child having trouble with organization may be to put toys in proper locations in the classroom during clean-up time. For another child with problems in megacognition, a goal could be to develop problem-solving skills with a peer, for example, by making minor adjustments when completing a puzzle after the first attempt fails. The goal of another child could involve sustained attention by completing an art project before going to the reading center to find a book. For this executive function skill, a child may develop a positive mindset, that is, beliefs and expectations about self and others. Finally, if a child has trouble with flexibility, a possible goal could support her or him during transitions to adjust to changes in routines and class activities. Teachers can create a wide variety of opportunities for role modeling and providing guided practice for executive functioning in the classroom as well as opportunities for independent practice (see Figure 2).

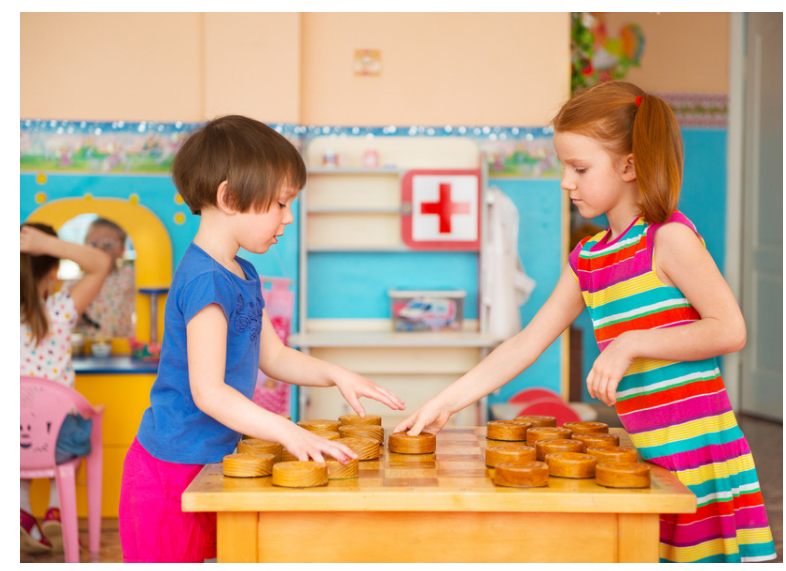

Figure 2. Peer buddy programs provide one-on-one support for children to learn academic skills in a variety of early childhood settings

\section{Step 4: Selecting Peer Buddies}

The success of an effective program supporting executive functioning is often connected to the types of peer buddies invited to participate and teach executive function skills. To identify the positive executive function skills that would be selected for increase in children who 
would participate with the peer buddy program, the teacher should measure child attributes essential to the social area of development. Despite the lack of a single formula or recipe for selecting peer buddies, they should demonstrate (a) social competence, (b) social responsiveness, (c) responsibility in following teacher directions, and (d) age-appropriate play skills (Bellini, 2006). For example, appropriate peer buddy skills and dispositions may include good listening skills by showing interest, friendliness (e.g., smiling, nodding), and good communication skills for explaining rules and helping a child feel good. Table 3 describes a list of dispositions desirable in peer buddies. Through observation, interviews with family members, and strong ratings and results from curriculum-based and social-development assessments, teachers can select peer buddies who are positive role models. One approach for selecting them may involve interests and classroom activities (e.g., favorite toys, sports, or favorite movie or TV characters) shared with the children who will receive training in executive function skills. Careful selection by teachers ensures a mutual decision between the peer buddy and child receiving the executive function skill intervention. For example, a child may want to keep the same peer buddy for the entire school year or change and rotate to include new buddies, depending on the executive function skill supported. This method for selecting peer buddies may result in new friendships.

A second approach to selecting peer buddies involves considering the children in the classroom in terms of their strengths, defined as the ability to provide consistent, near-perfect performance in a given activity (Winseman, Clifton, \& Liesveld, 2008). Each child has a unique biological makeup with a combination of talents and strengths that can be developed and implemented to different situations (Clifton \& Anderson, 2002). Strengths have the potential to empower peers and begin with talents that represent a capacity to do something (Clifton \& Anderson, 2002). Early childhood teachers can identify the strengths of potential peer buddies when taking class observation notes, digital pictures during play time and class activities, or by using social skill assessments. Peer strengths could include being responsible, having respect for others, enthusiastic and having a positive attitude, or being adaptable to changes. For example, if a child's strength is completing work in a timely fashion, this peer could support a child who lacks executive function skills in the areas of goal-directed persistence, sustained attention, or task initiation. A child in the class may be an initiator who likes to make plans before starting a project or when playing with friends could be a peer buddy to support a child who needs to develop planning and organizational executive function skills. One who is empathic and kind to others and can respond to feelings could support a child who has trouble with emotional control. Finally, a child who likes to learn new things and remembers new information easily could help a classmate lacking these skills develop a stronger working memory. Strengths have potential as very powerful tools in a peer buddy program when used in concert with a child's knowledge, basic life skills, and talents. 
Table 3. Peer Buddy Dispositions for Teaching Executive Function Skills

\section{Peer Buddy Dispositions for Teaching Executive Function Skills}

- Friendliness exhibited by smiling when talking with friends and caring about others' feelings by using kind words during play and class activities; enjoys making new friends

- Ability to take turns with toys and materials during play time with friends and class activities

- Effective listening skills, including showing interest and using eye contact when talking to a friend; outgoing when approaching new friends in class and likes to initiate conversations with friends

- Citizenship skills exhibited by understanding the rights and duties of others; obeys class rules and contributes to the democratic atmosphere of the classroom community as a leader and role model to others

- Effective communication and active listening exhibited by asking questions and talking over a problem and suggesting alternative solutions if a conflict arises during playtime

- Sense of humor with friends, cheerful; likes to join in play with friends, makes others feel special and appreciated

- Patience with friends during class activities exhibited by waiting for a friend so both can go together to the next activity; a team player who helps friends to do their best in any situation

- Understanding of others' needs exhibited by recognizing that everyone has different interests; likes to include everyone in the class; leaves no one out during large-group class activities

- Follows directions when given a two- or three-step activity; likes to make a plan before starting a project; organized and follows through with a class activity from start to finish

- Acts as a cheerleader by encouraging others to continue and complete an activity; makes others feel happy by showing a positive attitude

- Takes risks appropriately by suggesting alternative solutions during playtime or when playing with peers to try new ideas, toys, games, and ways to complete an activity

- Empathy shown toward classmates exhibited by ability to understand how another person feels; helps another child recognize that mistakes are experiences from which to learn

- Confident and responsible; exhibits leadership by volunteering to assist the teacher with class activities; often the first child in the class who raises hand to solve a problem or answer a question

- Exhibits curiosity by gathering information and asking questions; enjoys learning and remembering more information than others in the class; likes to learn new things every day and is happy when remembering new information 
Table 4. Visual and Verbal Strategies to Support Peer Buddies in Developing Executive Function Skills

\section{Visual Strategies}

- Activity schedules: Assist children to focus on the next activity; contain pictures or words; may include activities of the day or the sequence of events to be completed

- Transition digital books: Teachers can use photographs or clip art to represent the schedule and activity choices. A transition book can be made into a book using a folder or downloaded on the iPad for the peer to use with his or her friend.

- Sequence strips: Steps for completing a task or activity can be placed on a strip of cut construction paper or cardboard. Sequence strips may include pictures, photographs, words, or symbols.

- Simple signals: Cards or flashcards can be used as visual cues to stay focused, pay attention, remain calm, or ask a question.

- Colored bracelets: The peer buddy and friend can select matching colored bracelets when selecting activities. Wearing the bracelets reminds the pair to complete one task or activity before selecting bracelets of another color.

- Choice strips: Peer buddies can use choice strips with a friend who has difficulty transitioning to an activity or has limited language to describe, plan, and compete an activity.

- Social stories: Social stories written by teachers and/or with peer buddies enable individualization in a story created in a child-specific format. Specifically, the stories are written in a simple language reflecting the child's and peer buddy's developmental level and focus on a particular executive function skill.

\section{Verbal Strategies}

- Prompts: Verbal prompts are specific to individual children to remind them of their assigned roles (e.g., taking turns, staying focused on an activity, completing an activity, remaining calm) for developing a specific executive function skill.

\section{Step 5: Developing Activities for Achieving Goals and Setting up the Classroom}

Activities should be developed around a specific executive function skill and the interests of the peer buddy and the classmate. For example, if a child has difficulty with focusing on daily transitions in the classroom, the teacher may assign a peer buddy during transition times, which can be difficult because they cause everything to shift: the physical space, teacher's 
tone of voice, choice of words, movement, and children's choices about what they want to do versus doing what they are told to do (Cooper-Kahn \& Foster, 2013). To assist the peer buddy, the teacher can consider providing a small job for the child to focus on during the transition, such as announcing snack time to the class or taking the hand of a peer when transitioning the class to the library. The peer buddy can often give an advance warning before the transition takes place; for example, the peer buddy can preview the transition for the child by providing visual and verbal supports, such as telling the child about the upcoming transition. Visual supports may include picture schedules showing step-by-step sequences for an activity, picture prompts with photos, sticker charts, or picture exchange communication system boards. Peer buddies can also use visual cues with picture cards, checklists, flashcards, calendars, scripts, or social stories by giving step-by-step instructions of the upcoming event. Table 4 offers a list of visual and verbal strategies peer buddies can use during the class program to develop executive function skills. Taking step-by-step approaches, using visual organizational aids, and prompting directly may lend extra support to the child who needs to develop stronger executive function skills. Finally, teachers should remember that any peer buddy program supporting the development of executive function skills should be flexible and individualized to meet the needs of the child requiring help.

\section{Step 6: Training and Supporting Peer Buddies}

Good candidates for peer buddies are those children with whom others can work successfully (Dawson \& Guare, 2009). Teaching peer buddies how to interact and communicate with children with weaknesses in executive function skills is an important component for the classroom program. Peers should be involved in the training: Teachers should encourage peer buddies to ask questions and brainstorm activities that the child who needs help might like to do together as a team. Teachers can also model for peers how to initiate conversations with the child and prompt him or her to accomplish a particular target behavior or executive function skill. During training, peer buddies may need help understanding the importance of supporting a child who needs to develop executive functioning in the classroom: The teacher may identify ways they can play together or emphasize the necessity of the particular executive function skill in building a strong classroom community. Holding conversations with a peer buddy and role modeling classroom situations with him or her may increase empathy and support problem solving. The teacher may say to the peer, "Paul, I'm so glad you are going to be Ryan's peer buddy today! Sometimes Ryan has a hard time paying attention during circle time. You can sit next to him during circle time and help him with the calendar by counting the days of the week and pointing to each numeral on the calendar and assisting with graphing the temperature and weather today." Teaching the peer buddy to praise the child he or she is supporting is also very important. Forms of positive reinforcement peer buddies can use include stickers, verbal rewards, nonverbal gestures, playing with a favorite toy with the peer buddy, or small tokens given by the peer buddy, such as toys from a treasure chest.

Finally, one aspect of this step in establishing a peer buddy program that teachers sometimes forget is encouraging the peer buddies' efforts and praising their successes. During training the peer buddy can be praised for performing duties and responsibilities and given positive 
reinforcement, such as extra time at the computer or iPad during free play or a note sent home to the family. Positively reinforcing the peer buddy in this manner may increase the likelihood of strengthening the executive functioning of the child receiving the training.

\section{Step 7: Collecting Data and Monitoring Progress}

As with any social skill intervention package, analyzing data to determine the level of success is critical (Heflin \& Simpson, 1998). Data should be collected and monitored during initial peer buddy training. A valid data collection system should be developed by the teacher for analyzing students' goals. For example, teachers can easily develop a simple checklist or quick tally to graph the increase in executive function skills for individual children as well as the class. Questions to consider during the evaluation process could be the following: What aspects of the peer buddy program were successful in developing stronger executive function skills? What road blocks or problems occurred during the program? What changes could improve the peer buddy program for the entire class? How could families be more involved with the program? After careful reflection, this information can also be shared with families and administrators. To verify that teachers trained peers to use PMI with fidelity during the peer buddy program, a fidelity checklist is encouraged. . Throughout the entire process, teachers should monitor goals very carefully over time to ensure that progress is current and complete.

\section{Step 8: Maintaining the Peer Buddy Program Supporting Executive Functioning}

The teacher is the primary agent responsible for determining when, where, and how long the peer buddy program should last. Mounting a peer buddy board in the classroom such as "Fantastic Friends," at the beginning of the program may be beneficial; pictures of the children can be posted on the board as well as notes about friendship, taking turns, following directions, and completing class activities. During circle time or daily family meetings, children could develop a peer buddy manual with ideas and rules from everyone, so all children can participate in the program. Opportunities for role-playing and providing intentional, personalized, and authentic activities for developing executive function skills should be available throughout the day for generalization. For example, in a preschool or kindergarten classroom, opportunities may occur during play time, snack time, recess, circle time, and dismissal. After each peer buddy session, the teacher should allow time for all children to document and evaluate their work together by drawing pictures, taking digital pictures, dictating stories to the teacher in journals, creating a personal journal, or posting documentation on boards in the classroom.

\section{Conclusion}

In recent years interest in executive functioning has increased (Yeager \& Yeager, 2013). Understanding the development of executive function skills during the early childhood years is particularly important as shown in several longitudinal studies that provided evidence that both inhibitory control and working memory skills reliably predict early learning achievement in school, particularly in the areas of math and literacy (Blair \& Razza, 2007; Ponitz, McClelland, Matthews, \& Morrison, 2009). Young children can develop executive 
function skills to keep themselves from talking during inappropriate times, to participate in circle time amid distractions, to remember to raise their hands and follow directions, and to focus and complete a multitask math activity; doing so may provide the foundation necessary for robust learning in a classroom setting (Beer et al., 2014).

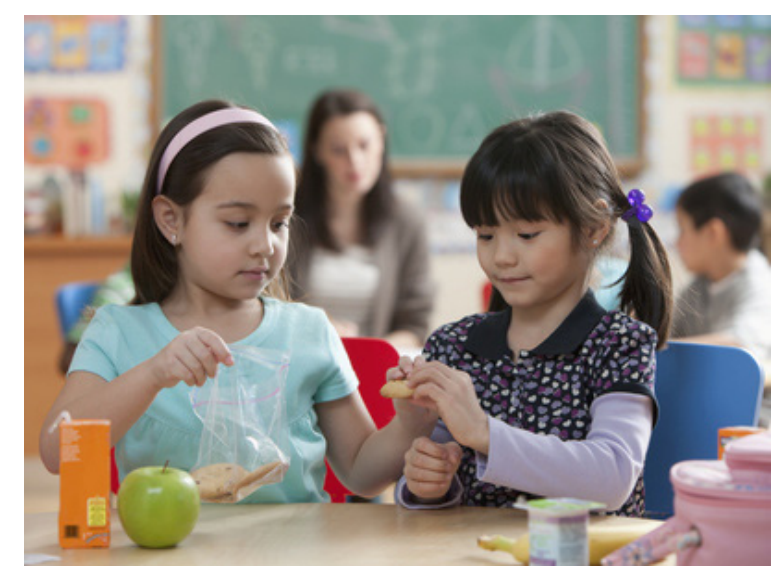

Figure 3. Peer buddies develop new friendships and help build a caring classroom community

Executive function skills are self-directed mental processes that organize behaviors, allowing children to direct their actions toward a goal (Barkley, 1997). These self-directed mental processes occur during a delay in responding to an event, serve to modify or transition the eventual response, and ameliorate future consequences related to the event (Barkley, 1997). Evidence has shown that developing executive function skills during the early childhood years has the potential to benefit children (Dawson \& Guare, 2009). Using a peer buddy program provides a practical and effective method to develop and support executive functioning for all young children. Those receiving support from peers gain new opportunities to develop task initiation and planning skills, persistence, sustained attention, emotional control, working memory, and response inhibition. Peer buddies participating in a class-wide program have opportunities to increase leadership, create new friendships, and strengthen their own executive function skills, which can contribute significantly to their development, lead to a lifetime of stronger academic success, and lay the foundation for increased confidence and self-esteem needed to manage life tasks of all types and achieve new dreams (see Figure 3). All young children should be supported in their strengths and dreams. By supporting young children in their efforts to develop stronger executive function skills, teachers build resilience and help them discover their inner strengths for facilitating better social interactions, stronger problem-solving skills, and confidence in cognitive decision making to be successful citizens at home and in school.

\section{References}

Barkley, R. A. (1997). Behavioral inhibition, sustained attention, and executive functions: Constructing a unifying theory of ADHD. Psychological Bulletin, 121, 65-94. 
http://dx.doi.org/10.1037/10033-2909.12/.165

Beer, J., Kronenberger, W. G., Castellanos, I., Colson, B. G., Henning, S. C., \& Pisoni, D. B. (2014). Executive functioning skills in preschool-age children with cochlear implants. Journal of Speech, Language, and Hearing Research, 57, 1521-1534. http://dx.doi:10.1044/2014-JSLHR-H-13-0054

Bellini, S. (2006). Building social relationships: A systematic approach to teaching social Interaction skills to children and adolescents with autism spectrum disorders and other social difficulties. Shawnee Mission, Kansas: Autism Asperger Publishing Company.

Blair, C., \& Razza, R. P. (2007). Relating effortful control, executive function, and false belief understanding to emerging math and literacy ability in kindergarten. Child Development, 78, 647-663. http://dx.doi.org/10.1111/J.1467-8624.2007.010.19.x

Brown, W. H., Odom, S. L., McConnell, S.R., \& Rathel, J. M. (2008). Peer interaction interventions for preschool children with developmental difficulties. In W. H. Brown, S. L. Odom, \& S. R. McConnell (Eds.), Social competence of young children: Risk, disability, \& intervention (pp. 141-160). Baltimore, MD: Brookes.

Carpenter, M., Nagell, K., \& Tomasello, J. (1998). Social cognition, joint attention, and communicative competence from 9 to 15 months of age. Monographs of the Society for Research in Child Development, 63(4), 167-174. http://dx.doi.org/10.2307/1166214

Carter, E. W., Cushing, L. S., Clark, N. M., \& Kennedy, C. H. (2005). Effects of peer support interventions on students' access to the general curriculum and social interactions. Research \& Practice for Persons with Severe Disabilities, 30(1), 15-25. http://dx.doi.org/10.2511/rspd.30.1.15

Cartwright, K. B. (2012). Insights from cognitive neuroscience: The importance of executive function for early reading development and education. Early Education and Development, 23, 1-13. http://dx.doi.org/10.1080/10409289.2011.615025

Clifton, D. O., \& Anderson, E. (2002). Strengths Quest: Discover and develop your strengths in academics, career, and beyond. Washington, DC: The Gallup Organization.

Collins, M. (2005). Young buddies: Teaching peer support to children 6 to 11. London, UK: Chapman.

Cooper-Kahn, J., \& Dietzel, L. C. (2008). Late, lost, and unprepared: A parents guide to helping children with executive skill functioning. Bethesda, MD: Woodbine House.

Cooper-Kahn, J., \& Foster, M. (2013). Boosting executive skills in the classroom: A practical guide for educators. San Francisco, CA: Jossey-Bass.

Copeland, S. R., McCall, J., Williams, C. R., Guth, C., Carter, E. W., Fowler, S. E., Hughes, C. (2002). High school peer buddies: A win-win situation. Teaching Exceptional Children, $35(1), 16-21$.

Dawson, P., \& Guare, R. (2009). Smart but scattered: The revolutionary "executive skills" 
approach to helping kids reach their potential. New York, NY: Guilford Press.

Dawson, P., \& Guare, R. (2010). Dawson, P., \& Guare, R. (2010). Executive skills in children and adolescents: A practical guide to assessment and intervention. New York, NY: The Guildford Press.

Dawson, P., \& Guare, R. (2012). Coaching students with executive skills deficits. New York, NY: Guilford Press.

English, K., Goldstein, H., Shafer, K., \& Kaczmarek, L. (1997). Interaction among preschoolers with and without disabilities: Effects of a buddy skills-training program. Exceptional Children, 63, 229-243. http://dx.doi.org/10.1044/JS/hr.4001.33

Gewirtz, S., Stanton-Chapman, T., \& Reeve, R. (2009). Can inhibition at preschool age predict ADHD symptoms and social difficulties in third grade? Early Child Development and Care, 179, 353-368. http://dx.doi.org/10.1080/03000443060/119885

Gresham, F. M., \& Elliott, S. N. (2008). Social skills improvement system (SSIS) rating scales. Minneapolis, MN: Pearson.

Grisham-Brown, J., Hemmeter, M. L., Pretti-Frontczak, K. (2005). Blended practices for teaching young children in inclusive settings. Baltimore, MD: Brookes.

Helflin, L. J., \& Simpson, R. L. (1998). Interventions for children and youth with autism: Prudent choices in a world of exaggerated claims and empty promises. Part II: Legal/policy analysis and recommendations for selecting interventions and treatments. Focus on Autism and Other Developmental Disabilities, 13, 212-220.

Hughes, C. (1998). Executive function in preschoolers: Links with theory of mind and verbal ability. British Journal of Developmental Psychology, 16, 233-253. http://dx.doi.org/10.1111/J.2044-835x.1998.tb00921x

Hughes, C., \& Carter, E. W. (2006). Success for all students: Promoting inclusion in secondary Schools through peer buddy program. Boston, MA: Allyn \& Bacon.

Hughes, C., \& Ensor, R. (2008). Does executive function matter for preschoolers' problem behaviors? Journal of Abnormal Child Psychology, 36, 1-14. http://dx.doi.org/10.1007/s10802-007-9107.6

Jackson, J. N., \& Campbell, J. M. (2009). Teachers' peer buddy selections for children with Autism: Social characteristics and relationship with peer nominations. Journal Autism Developmental Disorders, 39, 269-277. http://dx.doi.org/10.1007/s10803-008-0623-1

Laushey, K. M., \& Heflin, J. (2000). Enhancing social skills of kindergarten children with autism through the training of multiple peers as tutors. Journal of Autism and Developmental Disorders, 30, 183-193.

Mathur, S. R., \& Rutherford, R. B. (1991). Peer mediated interventions promoting social skills of children and youth with behavioral disorders. Education and Treatment of Children, 14(3), $227-243$. 
McCormick, L. (1997). Language intervention and support. In L. McCormick, D. F. Loeb, \& R. L. Schiefelbusch (Eds.), Supporting children with communication difficulties in Inclusive settings: School-based language intervention (pp. 257-306). Boston, MA: Allyn \& Bacon.

Missall, K., \& Hojnoski, R. L. (2008). The critical nature of young children's emerging peer-related social competence for transition to school. In W. H. Brown, S. L. Odom, \& S. McConnell (Eds.), Social competence of young children: Risk, disability, and intervention (pp. 117-137). Baltimore, MD: Brookes.

Montgomery, D. E., \& Koeltzow, T. E. (2010). A review of the day-night task: The Stroop paradigm and interference control in young children. Developmental Review, 30, 308-330. http://dx.doi.org/10.1016/j.dr.2010.07.001

Plumer, P. J, \& Stoner, G. (2005). The relative effects of classwide peer tutoring and peer coaching on the positive social behaviors of children with ADHD. Journal of Attention Disorders, 9(1), 290-300.

Plumer, P. J. (2007). Using peers as intervention agents to improve the social behaviors of elementary-aged children with attention deficit hyperactivity disorder: Effects of a peer coaching package. Dissertation abstracts international: Section A. Humanities and social sciences, 68(7) 2813.

Ponitz, C. C., McClelland, M. M., Mattthews, J. S., \& Morrison, F. J. (2009). A structured observation of behavioral self-regulation and its contribution to kindergarten outcomes. Developmental Psychology, 45, 605-619. http://dx.doi.org/10.1037.a0015365

Sansosti, F. J. (2010). Teaching social skills to children with autism spectrum disorders using tiers of support: A guide for school-based professionals. Psychology in the Schools, 47, 257-281. http://dx.doi.org/10.1002/pits.20469

Suchy, Y. (2009). Executive functioning: Overview, assessment, and research issues for non-neuropsychologists. American Behavioral Medicine, 37(2), 106-116. http://dx.doi.org/10.1007/s12160-009-9097-4

Winseman, A. L., Clifton, D. O., \& Liesveld, C. (2008). Living your strengths. New York, NY: Gallup Press.

Yeager, M., \& Yeager, D. (2013). Executive function and child develop. New York, NY: Norton.

\section{Copyright Disclaimer}

Copyright reserved by the author(s).

This article is an open-access article distributed under the terms and conditions of the Creative Commons Attribution license (http://creativecommons.org/licenses/by/3.0/). 